\title{
A Vibrant, Pluralistic Sustainable Water Management Measures under Climate Robustness Analysis and the Uncertainty of Demand in Arid Environments
}

\author{
C.Y.J. Chen \\ King Abdulaziz University, Jeddah 21589, Saudi Arabia \\ St Petersburg State Univ, St Petersburg 199034, Russia \\ Taiwan Water Corporation, Taichung 40455, TW (ROC) \\ jc343965@gmail.com
}

\begin{abstract}
Taking into account the uncertainty of future water shortages and climate change and demand, policy makers need to analyze technical resources in sustainable management. By "sustainable" is not clearly defined, but for resource evaluation index by using traditional static weather and demand, limiting the analysis variables to the limited flexibility of options specific water-based and time proposed. This work presents a robust, diverse, dynamic and continuous evaluation of technologies and corresponding performance indicators, called Sustainable Development (MOS) measurement of resource management is better suited to withstand future parameters. Range of potential future climate scenarios and requirements calibrate hydrological model in extreme natural and man-made water stress in arid basin as an example an example. Comparison of MOS and recommendations water management plans cost rankings, the paper determines the traditional evaluation method not only underestimated the future water deficit, but also to support solutions without taking into account supply and demand uncertainty. And in view of future climate and resource-dependent market trajectory uncertainty of the MOS method, proposed solutions, though perhaps not optimal, it is robust future change parameter values, and therefore one of the best water management solutions random natural worlds.
\end{abstract}

Keywords: sustainability assessment; arid zone hydrology; watershed modeling; groundwater; water supply; system analysis; predicative modeling; climate change; sociohydrology; vulnerability.

\section{INTRODUCTION}

Water surrounds us, falling from the sky, rushing down the river, from the tap water, but many of us never stop to ask where it comes from. The answer is a complex, stretching far beyond a heavy rain cloud or cramps, back to the very origin of the universe all the way. Shortly after the Big Bang, protons, neutrons, and electrons in high-temperature 10 billion kilowatt swarmed. Within minutes, hydrogen and helium, is called the lighter elements in a shape is called nucleosynthesis processes have been taken by these atomic building blocks. (Lithium has a cameo as well.) The heavier elements did not occur until much later, when the lighter elements inside stars and in supernova fusion. Over time, these stars heavy elements, including oxygen, into space, they used the lighter elements mixed waves sent.

Water governance, much like the system, management efforts must be adaptive and resilient. Resilience is the capacity of social-ecological systems to absorb disturbances while undergoing change and still remains substantially the same function, structure, identity restructuring and feedback [1]. The method we use the term to describe an adaptive adjustment in response to new knowledge, 


\section{C.Y.J. Chen}

and having a support system toughness [1,2] ability. Based adaptive management flexibility is rooted in the social, legal and scientific knowledge is crucial values and different stakeholders of the world into the resource management, the use of the best available scientific [3,4,5] decision-making process. The decision-making process must be iterative, ongoing, and is capable of changing science in the social and biophysical systems to deal with uncertainty.

We in the human world [6]; the impact of human impact on global change now create more complex environmental conditions as the main driving force of the ecosystem and human health. In the 1960s and 1970s, the United States developed policies and laws, such as the National Environmental Policy Act (NEPA), the Clean Air Act (CAA), Clean Water Act (CWA) and the Endangered Species Act (ESA), which efforts to assess risk and protect the environment while at the same time, taking into account the population $[7,8,9,10]$ the country's economic and social needs. In fact, NEPA purpose statement claims that this is "a national policy to encourage productive and enjoyable harmony between man and the environment." [7]. Basis for policy and legislation, which will help alleviate the problem, such as point source pollution; however, it comes to managing the impact of climate change, non-point source pollution and public [11] and so the tragedy of ecosystem services and complex environmental challenges across jurisdictions still, if no more questions today.

Policies, such as the National Environmental Protection Agency, and the law, such as CWA, CAA and ESA, in response to man-made environmental degradation was adopted and acknowledged "restore and maintain the environmental quality of the importance of" [7]. Years of case law in the definition of science these institutions into the responsibilities and the role of management and the way the national and state organs. Has taken scientific method requires identifying and resolving problems in the production process of social participation, and thus decided to develop transparent and mutual respect social needs and different worldviews [12,13,14,15]. Social Science Nexus is so thoroughly intertwined, said: "Neither science nor democracy can be strengthened in the absence of other people's welfare." [16] (XIII). For science, ecosystem ecology helps to understand human beings are an integral part of all ecosystems, but our understanding of ecosystems and their changes over time. Natural resource management using a theoretical framework for adaptive management to manage the system of scientific knowledge is provisional. It tells us that we should be monitored by the results of scientific study design management programs, and then adjusted accordingly [17]. It is built on including key premise: (1) significant connection is determined; (2) structural features are more important than digital measurement; (3) changes in a variable can have an unexpected impact; (4) monitoring a variable may seem showed no change, dramatic change is imminent $[2,12,18]$. Adaptive management system, we must acknowledge that uncertainty, surprise, two dynamic and complex feedback variability inherent and its kinetics [19]. The concept toughness integrated into this framework encourages us to manage the function and structure, the ecosystem services upon which we depend is available for current and future generations [20]. Finally, adaptability and resilience management system by biophysical historical backgrounds, different values and world domination occurs within the dynamic social system.

Water resources management in the United States from the past delivered only with a sufficient quantity and quality of initial concern Evolution. This traditional method is through integrated water resources management (IWRM), namely the number of efforts, the quality of surface water and groundwater dynamics, and ecosystem services into an adaptive, flexible governance framework that can across jurisdictional boundaries [21 largely replaced]. Hydrological system management decisionmaking and participation historical issues, such as the diversion of the river water rights and infrastructure within the plurality of participants and entities. Complexity within the scope of 


\section{C.Y.J. Chen}

integrated water resources management decisions require people to participate in the management of water resources in the border, it may be the system, culture, space and time, or it takes a dynamic view, rather than linear [22] Social Ecology - hydrological system . In addition, integrated water resources management must bridge the gap $[23,24]$ between the water and the multi-jurisdictional decision science.

Model and modeling process has been considered a useful tool for the integration of the information society, the economy and the environment, to facilitate complex environmental management issues and decisions [12,25,26,27,28,29,30,31]. "Alternative model [AS] a true system of" we describe [32]. The behavior of the model can be used for learning or communication systems over time. The model can be as simple as a picture or chart. Model may be a natural process, such as a tunnel or a physical representation of the flow table. Model can describe causal relationship causal loop diagram (CLD) through characterization. Mathematical computer models can be used to simulate multiple parameters over time behavior. These representations of reality can be used to recognize individuals or groups of individuals to communicate, or they can be used to calculate the physical processes, such as the flow of water through the water to help us understand, and how to move through a landscape. The model building process first creates mental models. Mental models are based on their own understanding of how individuals experience $[33,34,35]$ represented around the world. These can be "ingrained assumptions, generalization, and even pictures or images [said] affects how we understand the world around us, and how we act." [34]. Our language of communication and image of mental models. Communication and analysis of our understanding of the complexity of the system may also need to use systems thinking tools, such as describing the relationship and causality $[34,36]$ causal diagram. Although mental model for us and may we conduct our daily lives, as well as systems thinking can help us to look at the complex relationship around us, computing a plurality of parameters, but over time, the feedback between these parameters between relationship, you need to use a computer [27, $32,36,37]$. Integrated computer models of social, economic and environmental information is effective and integrated research and decision-making [25,30,37,38,39,40]. Including hydrology experts and local stakeholders in cooperative architectural model social processes enable transparency and significant resistance, and helps to bridge science and water management $[12,31,37,39,41,42,43,44,45$ the gap between the $46,47,48,49]$. Best practices in the establishment of such models included in the model building process $[37,41,43]$ early, stakeholders often involved.

Collaborative Modeling (CM) is the integration of a variety of different stakeholders perspectives and facilitate discussion and to identify problems and make consensus-based, strategic method of rational management of space science. Dynamic equilibrium solution needs, while maintaining the values of respect for creation and innovation to explore what has been or is being made between what could be tight supply of space. As a stakeholder consultation group "problem solution" space, CM counselors seek from linear thinking and conflict are often deep-rooted values or worldview [42,43,44,48] Results transition people away. While the conflict will progress in unproductive ways, creating unfavorable results should be noted that the conflict is not necessarily a bad thing in itself is very important. Driving potential conflict needs to be changed, and there is no conflict of human potential

may not actively adjust their pre-crisis system. This article describes the use of CM as providing people with visual possible future and reflect on the possibility is advantageous, which is a method of potential conflicts in advance desirable opportunities. Advantageously gap between futures and unpopular causes tension for change, innovation and creativity provided the impetus. We will consider this type of creative tension tension [34]. It is the process [34] The emergence of such a state by engaging in "creative tension" of the resilient and adaptive solutions. 


\section{C.Y.J. Chen}

In this paper, we describe the integrated participation from stakeholders, systems thinking and system dynamics, water and natural resource modeling discipline, and resource planning method collaborative modeling experience in the process. The purpose of this study, we defined broadly stakeholders. We CM process participants including decision-making, the local water resources and state personnel, contractors, consultants, non-governmental organizations, legal experts, elected officials, professionals, researchers and academic self-selected members of the public who are interested water resources management. The CM process has occurred in the Inland Northwest, in the Palouse Basin and Spokane basin. These two basins are bidirectional state and across the border in Idaho and Washington state. We will describe our work in these basins and how it has evolved over time as stakeholder efforts to develop adaptive and resilient water management collaborative governance.

\section{Methodology on Resource Allocation}

In this study, efficient resource allocation method (EA) evolutionary algorithm proposed a fair basis. In order to maintain effective centralized solution, the resulting redistribution quite get between agents, each agent having an impact on the entire system should be determined. In order to understand the best response for each agent coalition of others, through the parallel evolutionary algorithm $[15,24]$ development, so that agency while interacting with other people to solve their local optimization problem. Describes some key concepts of mathematics, the preliminaries are as follows.

\subsection{Definitions}

$I=\{1 \ldots N\}$ represents a group of agents. Suppose each agent $i$ control vector $x i \in$ Rni. So that $x$-it is not containing all policies, including proxy ix agents (distribution) vector. Receiving an allocation each agent through UI ximaximises utility function of his revenue. Strategy outline $X=(X 1, \ldots, X N)$ $\in \mathrm{Rn}+$ or simply $\mathrm{X}=$ utility UI (eleven $\mathrm{X}-\mathrm{i}$ ) of the UI $(\mathrm{X})=\mathrm{UI}$ (eleven X-I). Followings are defined.

:( Definition of central planners Welfare Maximisation (CP))

One solution is to maximize social welfare or central planning (CP) method, if it is given by the following optimization problem

$\mathrm{X} *=\operatorname{argmaxx} \Sigma \mathrm{i} \in \operatorname{Iui}(\mathrm{X})$

(CP)

Which is the sum of all the tools agents around the country. This results from the external observer was, if he / she is responsible for all proxy values.

:( Cooperation defined contribution)

Definition of $\mathrm{U} *=\Sigma \mathrm{j} \in \mathrm{Iuj}(\mathrm{X} *)$. Further, assume that the agent $\mathrm{i}$ decided to leave as a single cooperation and action (or separately), and let $U^{*}-i=\Sigma j \neq i$ iuj $\left(X *^{*}-i\right)$ is the sum of all other agents of income when I leave them . Acting on nine CP is defined as a solution,

$\mathrm{UI}=\mathrm{U} *-\mathrm{U} *-\mathrm{i}$

IX UI measures how much help CP agent solution. In other words, the user interface of the agent to leave the nine impact of cooperation.

The definition of fair :()

Income redistribution mechanism is fair, if each agent income following formula I:

$\mathrm{URI}=\alpha \times \mathrm{I} U *$ 
where,

$\alpha \mathrm{I}=\mathrm{u}^{-} \mathrm{i} \Sigma \mathrm{j} \mathrm{U}^{*}-\mathrm{j}$.

This means that each agent is based on his contribution to the CP solution is dispensed. This definition makes sense and has two indirect nature; (a) which is a balanced budget; that is, all the CP URI equivalent to the entire revenue values $\mathrm{U}^{*}$, where the mechanism to collect and agents from and expenses to convey word the sum of the single almost the same; and (B), it is reasonable; in other words, no agent has been lost by the participants (to each user's income is greater than zero). As mentioned above, make a greater contribution agents have higher incomes. In this case, agents are encouraged if they are given the following URI values determined by the revenue issue CP $\left(\mathrm{X}^{*}\right)$ derived constraints.

$\mathrm{U}^{*}$-i mean agents Nine, leaving all agents concentrated, competition for resources and independent agents $\{1,2, \ldots, \mathrm{I}-1, \mathrm{I}+1, \ldots, \mathrm{N}\}$. If the proxy IX to know other people's tactics, his strategy will be simple; he will select the rest of the utility maximization problem of single-agent problem. However, two problems through a proxy IX and agents form $\{1,2, \ldots, \mathrm{I}-1, \mathrm{I}+1, \ldots, \mathrm{N}\}$, should be addressed at the same time. This is because the best strategy depends on the agent $i$ and when he has left the group interaction and discovery $\mathrm{U} *$-ivalues, should not ignore the fact. Thus, $\mathrm{U} *$-i depends on two interrelated issues to maximize the utility of the agent $\{\mathrm{I}\}$, UI and agents' solutions form $\{1,2, \ldots, \mathrm{I}-1$, $\mathrm{I}+1, \ldots, \mathrm{N}\}$ summary utilities, $\Sigma \mathrm{j} \neq \mathrm{ij} \in \mathrm{Iuj}$ (Xi) shall at the same time to resolve. Parallel to deal with this next evolution of the technical definition of two distributed problems.

\subsection{Parallel Search Algorithm}

Here, the interrelated issues of a general class are formulated in which optimization problems in parallel simultaneously and interact with one another to solve. In the most general case where $\mathrm{n}$ agents and solve their problems alone, once each agent solve optimization problems, and interact with others seek their own optimal strategy. More specifically, since the $\mathrm{U}$ : radon radon $\rightarrow$ behalf of all $\mathrm{n}$ agents with the utility, $\mathrm{X}=(\mathrm{X} 1, \ldots, \mathrm{XN}) \in \mathrm{Rn}+$ is found by simultaneously solving the problem behind $\mathrm{n}$ :

Maxxisubjecttoui $(\mathrm{X}) \mathrm{x} \in \mathrm{Xi}$,

Wherein each agent UI nine vector control $x i \in$ Rni optimization utility (objective) function is subject to set Xicontainingx $\in \mathrm{Rn}+$ constraints. The relationship is described as the objective function and constraints in the skin depends on the decisions of other agents.

In order to solve the problem of $\mathrm{n}$ proxy $\mathrm{pi}, \mathrm{I}=1, \ldots, \mathrm{N}$ at the same time, every issue is dedicated to a proxy PI IX. Due to the presence of interconnection between each question vector $\mathrm{x}$, each problem will be solved, and it communicates with the other issues of shared information. $\mathrm{P}$ call all the problems children formation. Parallel genetic algorithm [25] in [24] and the development of coevolution [26] the idea be implemented to solve P idea is extended, so that each (sub) problem Pi has its own objective function. This concept [27] is used to obtain a faster convergence to the multiobjective optimization Pareto solution. So that $\mathrm{x}$-I that contains all the agents involved in the problem Pi does not include the vector agent $i$ of the decision variables. Search algorithm is executed in parallel by mapping $\hbar \mathrm{n}$ different search trail Description:

XT + 1 I = H (XT-I, XTI, PI),

Where $\mathrm{H}$ represents the interconnection between agents. H's role as agent nine synchronized map view of other decisions interacting agents in its vicinity, in order to optimize the problem Pi shown by 
$\mathrm{XT}$ - I remain fixed. ${ }^{\wedge} \mathrm{H}$ is described xivalue problem by updating the search Pi t-generation linking the first XI and X-i's. Since the problem Pi, each agent knows their component issues, and therefore through to the other neighboring agents $\mathrm{H}$ communicate, it has to explore the search space for local activities. Next, the algorithm 1 gives details of the search algorithm to solve the agency problem.

Each agent $\mathrm{i}$ for the formation of a dedicated search for the track $\mathrm{m}$ Population (line 1) by size. Popi is $\mathrm{m} \times$ NEI matrix and random padding. NEI is the number set by the neighboursi (2 lines) given the basic interaction agent. In other words, NEI equal agent decided a number of brokers in nine-plus neighbor. All individual $\mathrm{PK}=(\mathrm{X} 1, \ldots$, xnei $)$ each group I experienced a parallel search every generation reproduction tons (line 8). PB is reproduced from the other two different individuals within a population. If it's a better target than the PK, but it is still in the population that would otherwise be discarded (lines 9 and 10). At the end of each generation $t$, adjacent agent $(j \in$ neighboursi) to share its best individuals to form the population for the next generation of $T+1$ (12 lines) updates.

\section{The ObJective Function And Economic AnAlysis}

\subsection{Margin target function and sector-specific}

The benefits (ZOBJ) from the sum of the production (by a plurality of sectors and production sites $\mathrm{D}$ ) and environmental systems and services is formulated as

$\mathrm{ZOBJ}=\Sigma \mathrm{d} \Sigma \mathrm{sZPRDd}, \mathrm{S}+\Sigma \mathrm{nZENVn}$

Interests (1) wherein ZPRDd, S representing each production site $Đ$ consideration of three productive sectors (energy production, industry and agriculture), ZENVn the benefits from environmental flows.

Gross margin in specific sectors (ZPRDd, S) calculates the difference of economic wealth (or gains) (WPRDd, S), and cost:

ZPRDd, s = WPRDd, s-XPRDd, s-XENSd, s-XCNVd, s-XGWPd, s-XRUd, s-XENEFd, s-XE_EXPd,

s-XCNEd, s-XWAEd, s-XSPMXPd, s-XGPMXPd, s-XRPMXPd, s

where

XPRDd, s production costs (excluding energy and water costs, for example, material costs, wage labor, machinery hire sum, etc);

$\mathrm{XENSd}, \mathrm{s}$ is sent to the scene of the cost of producing energy commodities;

$\mathrm{XCNVd}, \mathrm{s}$ is the surface water to the costs of the production sector;

$\mathrm{XGWPd}, \mathrm{s}$ is the cost of production for industrial extraction of groundwater;

XRUd, $\mathrm{s}$ is the repeated use of the cost of backwater;

XENEFd, s to improve the energy efficiency of the cost (the cost of the efficient use of energy is the energy savings occurred in parallel with increased costs (energy efficient pumps, fluorescent light bulbs, etc.));

$\mathrm{XCNEd}, \mathrm{s}$ is the cost-effective transportation (transport efficiency by increasing the cost of transfer efficiency (e.g., to save a certain amount of water through the liner, a plastic cover, etc.) cost);

When XWAEd, $s$ is to improve the productive sector $\mathrm{S}$ (water use efficiency costs of water use efficiency costs by improving water use (such as in a particular field or in the production site to save a certain amount of water induced by the cost of implementing drip irrigation subsurface irrigation, etc.)); 
XE_EXPd, $s$ is the cost of expanding the power production capacity (capacity expansion costs of energy production plants (those costs required for example, by building additional power plants));

XSPMXPd, $\mathrm{s}$ is to expand the surface water supply costs (water pumping station and an extension (for example, through the construction of additional pumping occurs) these costs);

XGPMXPd, $\mathrm{s}$ is the expansion of groundwater pumping costs;

XRPMXPd, $s$ is the expansion of the drainage capacity of the pumping costs.

\subsection{Sector-specific Wealth (income) and Production Costs}

Wealth, expressed as the total revenue, the energy production sector, is considering calculate energy commodity prices (PED, O, T) and output (TPRDd, K, O, T):

WPRDd, 'ENR' $=\Sigma \mathrm{k} \Sigma \mathrm{o} \in \mathrm{KOLINK} \Sigma \mathrm{t}(\mathrm{PED}, \mathrm{o}, \mathrm{T}$ TPRDd, K, O, T)

At the same time, production costs in the energy sector multiplied by the average variable cost (for example, hiring labor costs, raw materials, etc.) of the total energy output of commodity computing.

In the industrial production sector (WPRDd, 'IND') it is considered to be equal to the increase in wealth (VAINDd) Industry Value:

WPRDd, 'IND' = VAINDd

Total income in the agricultural sector, calculation takes into account crop prices (PAC) and crop production output $(\mathrm{OAD}, \mathrm{C})$ :

WPRDd, "AGR '= $\Sigma \mathrm{C}(\mathrm{PAcOAd}, \mathrm{C})$

Crop production $(\mathrm{OAD}, \mathrm{C})$ to calculate crop yields and cultivated area of the product. Crop yields in turn depends on the monthly water scarcity. Cropped area is limited by the maximum available planting areas along the rivers. In the supplementary material (S83) - provided by equation (S77) showing the relationship between the use of additional formulations and crop yield potential irrigated area and water restrictions between. Irrigation site (at the field level considered here) cost of production costs than considering water and energy supply (such as fertilizers, chemicals, seeds, wages, etc.) and the cost of harvesting and post-harvest storage / transport.

\subsection{The Cost of Energy and Water Supply}

Energy supply is calculated as the cost of production:

XENSd, $\mathrm{S}=\sigma \mathrm{T}($ LoPEd, o, T TPRDUd, S, O, T)

$\mathrm{PED}, \mathrm{O}, \mathrm{t}$ is the price of energy commodities, TPRDUd, $\mathrm{S}, \mathrm{O}, \mathrm{T}$ is a sector $\mathrm{S}$ energy use for production operations.

Surface water costs (XCNVd, a plurality) is estimated as the sum of the cost of energy and pumping costs required to maintain a gravity feed water from the river for the node:

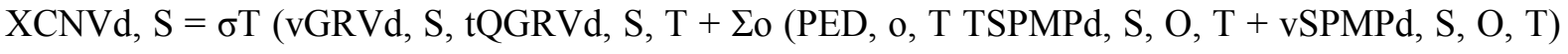
QSPMPd, S, O, T)

vGRVd, $\mathrm{S}, \mathrm{T}$ is a fixed cost per unit of surface water delivered by gravity;

vSPMPd, S, O, T is pumped each surface water (hire labor, operation and maintenance, etc.) unit costs;

TSPMPd, S, O, T is the surface water pumped per unit of energy demand;

QSPMPd, $\mathrm{S}, \mathrm{O}, \mathrm{t}$ is the amount of surface water pumping. 


\section{C.Y.J. Chen}

Groundwater irrigation supply energy cost calculation for electricity, the sum of diesel and other (operation and maintenance) for crops groundwater extraction charges:

XGWPd, S = $\sigma \mathrm{T}\left(\Sigma_{\mathrm{o}}(\mathrm{PED}, \mathrm{o}, \mathrm{T}\right.$ TGPMPd, S, O, T + vGPMPd, O, T) QGPMPd, S, O, T)

where

vGPMPd, $\mathrm{O}, \mathrm{t}$ is each pumping groundwater pumping units non-energy-related costs (hire labor, operation and maintenance, etc.);

TGPMPd, S, O, T is extracted by pumping groundwater per unit of energy consumption;

QGPMPd, $\mathrm{S}, \mathrm{O}, \mathrm{t}$ is the pumping of groundwater.

Total demand for use in backwater places cost is calculated as electricity, diesel and other (operation and maintenance) for groundwater extraction fee:

XRUd, S = $\sigma$ T ( $\left(\mathrm{O}_{\mathrm{o}}(\mathrm{PED}, \mathrm{o}, \mathrm{T}\right.$ TRPMPd, S, O, T + vRPMPd, S, O, T) QRPMPd, S, O, T) wherein

vRPMPd, S, O, T non-energy-related costs per unit of drainage pumping reuse (wage labor, operation and maintenance, etc.);

TRPMPd, $\mathrm{S}, \mathrm{O}, \mathrm{T}$ is the return per unit energy requirement of recycling;

QRPMPd, S, O, T is the amount of backwater recycling.

In the supplementary material (S23) - related to water and improve the productivity and energy efficiency of hydropower plants and pumping stations of different expansion costing details issued by the equation (S12).

INFLOW

\section{OUTFLOW}

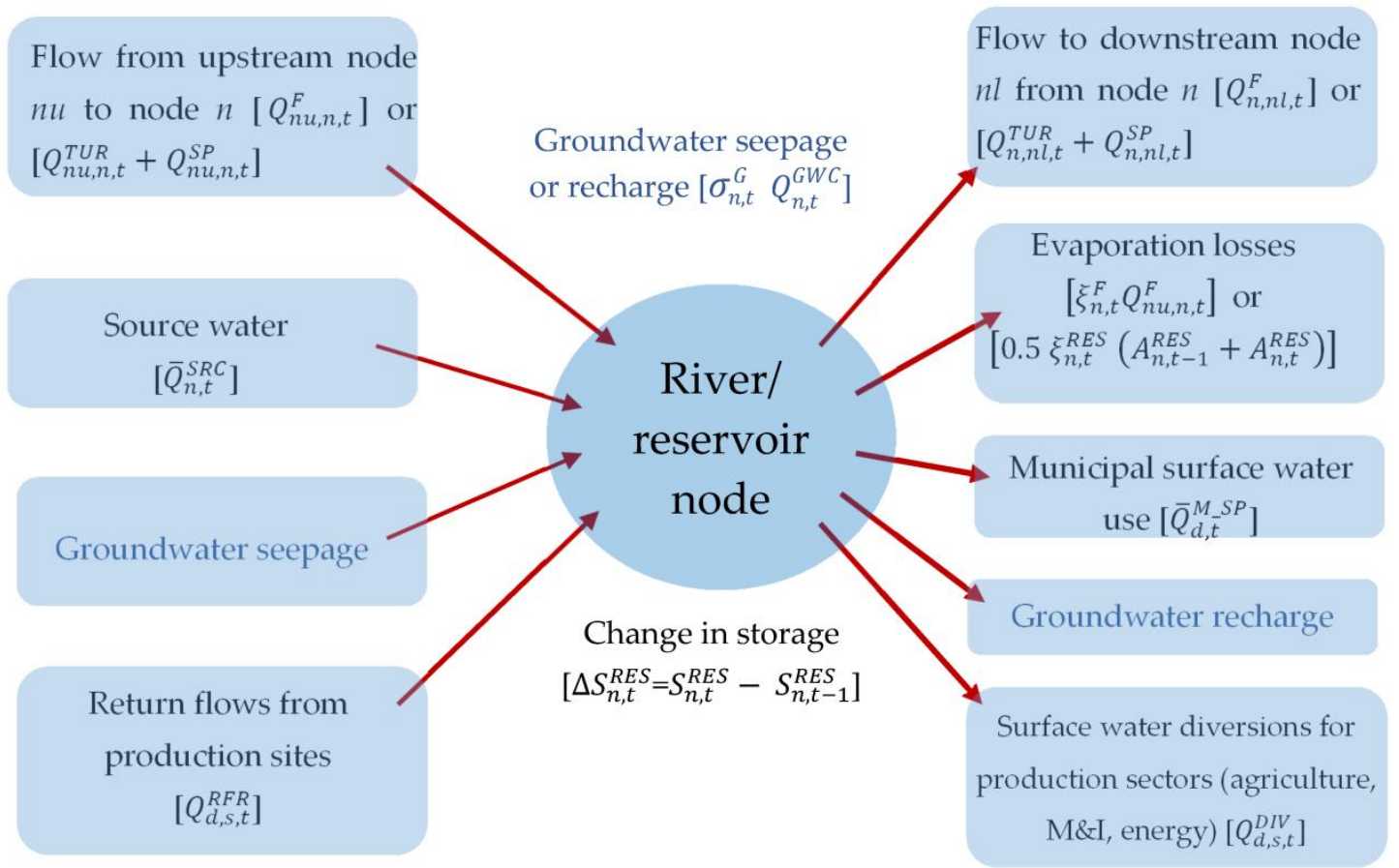

Figure 1. The system-wide economy - the node water energy balance model (SEVEN) river / reservoir - water. 


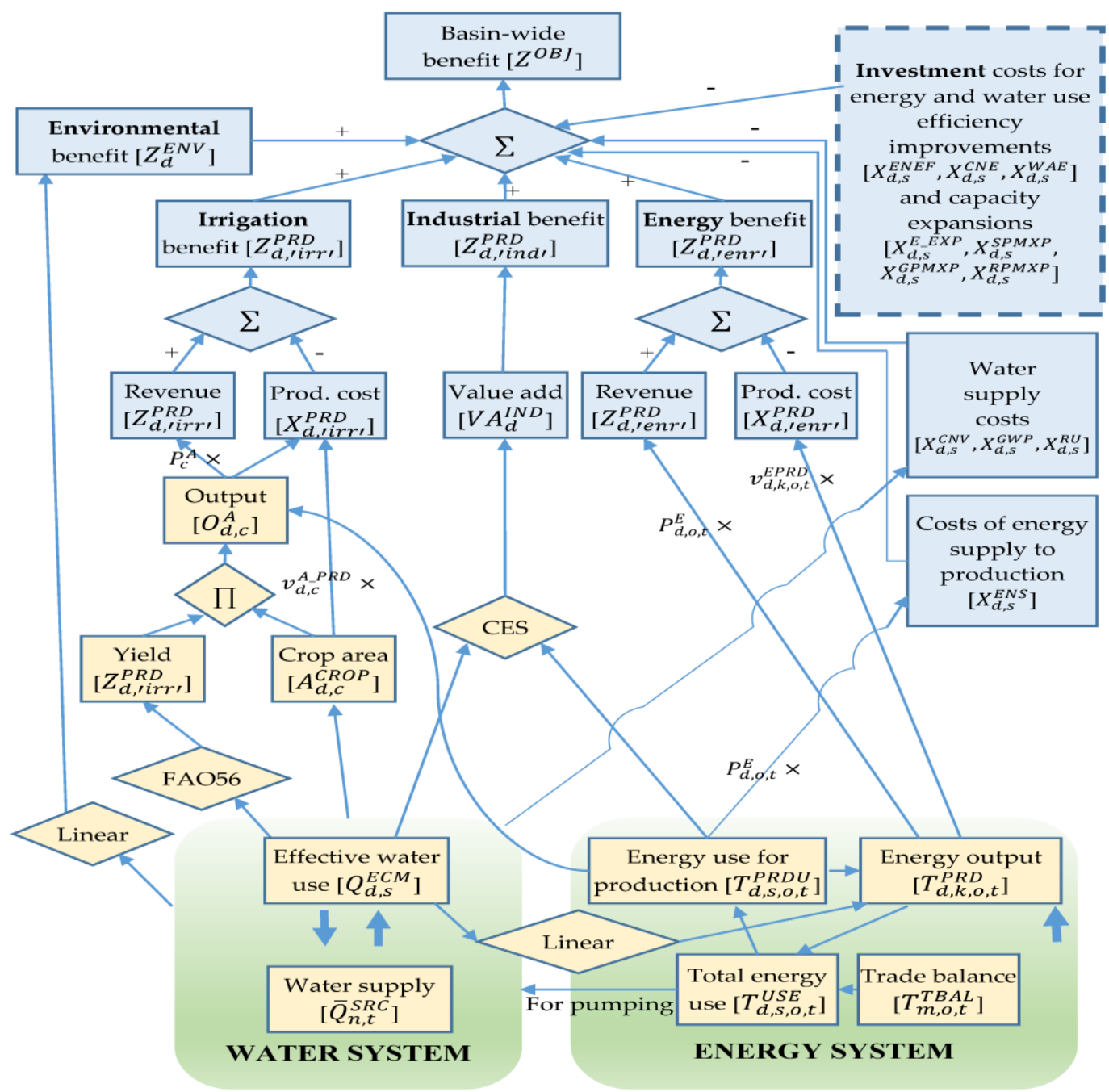

Figure 2. System-wide economy - water - energy model (SEWEM) structure. Source: Author's elaboration.

NOTE: Model variables rectangle; functional relationship between variables is diamond; arrows indicate the direction of the impact and the relationship that exists between the variables; light blue color pink for economic variables and physical measurement variables; green is used the system; CES constant elasticity of substitution; $\Pi$ multiplying function; $\Sigma$ summing function.

\section{RESUlts AND Discussion}

\subsection{Calibration of the basin demonstrations}

In equation (1) model, with each site (FIG. 3) of the four parameters individually calibrated, has been shown in 53 calibration pots, high capacity for reproducing observed streamflows, and NSE the values range from .64 to 0.93 and 0.77 average. For this basin in NSE value map in FIG. 4 (upper left panel) histogram in Fig. 5. From the latter, and the results can be observed, the average value of the sub-region $\mathrm{C}$ model provides higher than in the other two sub-regions of the results of the performance.

Water 0800209 G008 1024

Comparison of the performance obtained in FIG. 5 model (NSE) in step 1A (a) and step 2 (b) of analysis NSE index 4 (a) (average of the sub-region, and the mean, standard deviation, minimum and maximum values of all calibration pots) in different calibration stage (step 1A, step 1B, step 2); ( b) analysis (mean, standard deviation, minimum and maximum) of other performance indicators (ME = average error; $\mathrm{ME} / \mathrm{Q}^{---}$emp = dimensionless average error; RMSQ = root mean square error) 


\section{C.Y.J. Chen}

calibrated in the basin area (step 2). Corresponding to the optimum, minimum basin ID code, and the maximum performance indicators in parentheses report.

Suppose a1 each sub-region has been constant NSE terms provide A2, K, A 3, k and A4 in, k (step 1B), its corresponding performance, the new collection of the best values, are reported in the same histogram as Figure 4. The results are very similar to those discussed above (step 1A), represented in the model performance is not significantly reduced; average $2 \%$ decrease in the order of NSE index can be noted. NSE a significant decrease (from 0.73 to 0.44 ) has detected only for the ID 66 basin (sub-region $\mathrm{C}$ ), which is characterized by the highest value MAP second lowest value and $\mathrm{p}$.

As expected, the use of the equation (4) of AI, the evaluation parameter k (step 2) of regional relations, reducing the performance of the model with respect to the adoption of the best (step 1A and B) parameter set (Fig. 4 histogram). In fact, this performance degradation is the price to be able to provide free information site, a program to assess the runoff has to be paid. Nevertheless, the final performance of the model is maintained at an acceptable value range, NSE, satisfying performance that is equal to or more, according to Moriasi like performance levels. [60] for all calibration basin; only two exceptions are the above ID 66 basin (sub-region C), it has the lowest start, NSE values (ie, $\mathrm{NSE}=0.44$ in step 1B), and the ID 22 pots ( sub-region a), wherein, however, the resulting value, and $\mathrm{n}$ is equal to 0.33 and 0.35 , respectively. For this last basin, after the regionalization process, reducing the performance of the model is fairly consistent, because, after the step 1B, NSE is quite high (0.77). This may be attributed to the fact that after step 2 parameter values derived from this basin is the corresponding value obtained in step 1B significantly different, particularly with regard to parameters $\mathrm{a} 4$, the results of its value relative to the regionalization halved optimum value previously obtained (from 0.43 to 0.23 ) as.

NSE\% reduction after regionalization, with respect to calculated in step 1B of the NSE, all calibration range from 0.17 to $57 \%$, with an average of NSE (=0.69) than pots represent nearly $9 \%$ and reduce overall good performance. Reduction in efficiency for regionalization step 1A after a little more obvious, and NSE 11 percent average reduction. This comparison also highlighted in Figure 5, where the NSE (Fig. 5b) and the regionalization of parameters obtained and the process parameters set $1 \mathrm{~A}$ (Fig. 5a) is represented by the same color bar. Further, the process of regionalization, the model shows that, on average, higher accuracy in the sub-basin region $\mathrm{C}$, was 0.70 , the average enzyme. The ID 47 pots (sub-region C) has been shown at the top of each calibration phase NSE, the regionalized (step 2) is equal to about $3 \%$ decrease after performance.

Demonstrations, the second step protocol have also been used three statistical standards further observation and measurement of simulated monthly flow series between Assessment: average error, $\mathrm{ME}$ ( $\mathrm{mm} / \mathrm{month}$ ); dimensionless average error, $\mathrm{ME} / \mathrm{Q}^{--}{ }^{-} \mathrm{emp}$, is given by the ratio of the ME and the mean observed runoff $\left(\mathrm{Q}^{---} \mathrm{emp}\right)$ and between the root mean square error, RMSE ( $\left.\mathrm{mm} / \mathrm{month}\right)$. Each index, mean, standard deviation, minimum, maximum, and synthesis at optimum values for all calibration basin. The results of this analysis have demonstrated that respect for calibration (ie, NSE) the results of performance indicators, confirming the validity through the calibration process. This model has provided a satisfactory accuracy and can be considered unbiased in the world in all indicators analyzed by the relatively low value of the $\mathrm{ME}$ as proof. ME value, the absolute value is less than $3 \mathrm{~mm}$ basin analysis / month about $80 \%$, while the average $\mathrm{ME} / \mathrm{Q}^{--}$emp almost zero calibration basin. In terms of RMSE, the index has been the magnitude of the same order as those by the Cutore et al found a similar modeling methods. [47] in the basin ID 61,67 obtained simeto River 
sub-basin (Sicily, Italy), with the worst performance (about $45 \mathrm{~mm} / \mathrm{month}$ ), and 68, which are lowvalue basins correspond NSE in the average value of $(0.69,0.63$, and 0.58 , respectively).

Highest NSE basin (ie, ID 47) also provide satisfactory performance in terms of the ME, ME / $\mathrm{Q}^{---}$emp and root mean square error $(0.428,0.042,5.05 \mathrm{~mm} /$ month, respectively). NSE has the lowest basin (ie, numbers 22 and 66), showing the worst performance relative to other considerations statistical standards $\left(\mathrm{ME}=-6.67\right.$ and $-2.54 \mathrm{~mm} /$ month, $\mathrm{ME} / \mathrm{Q}^{---} \mathrm{emp}=-0.49$ and $-0.69, \mathrm{RMSE}=$ 15.37 and $9.97 \mathrm{~mm} /$ month, respectively). Only a basin (ID 40; the sub-region C) satisfactory NSE (0.63) related to other basin below average even for me (11 mm / month) and ME / Q provide value EMP (0.35), but it represents a weakness in other words, the equivalent obtained in the different studies worst performance (for example, [47]).

According to the report of observation and comparison of simulated runoff values monthly flow duration curve (First Day Cover) between 9 different representative basins. Four examples, with reference to the average performance is about equal in all calibration watershed basin, now reports: basin ID 18 may be considered to represent the mean NSE basin, basin ID 42 represents the average ME basin, basin ID 25 represents Basin average ME / $\mathrm{Q}^{---}$emp, and basin ID 59 represents the average RMSE basin. Furthermore, since during the fixed-dose combination usually depends considered, it has also been reported with the shortest (ID 45) and compare the longest (ID 23) of the sample size of the basin. Although the change in the calculation obscured some important details can flow complexing agent using monthly data in a fixed dose, rather than daily or higher resolution data, this analysis has confirmed the accuracy of the model is useful. For all tests basin, in fact, the model has been reproduced satisfactorily with the observed monthly runoff values related to size, from the lowest and the highest more frequent and rare human values, proved to be effective in the probability assessment of certain runoff value will equal or exceed.

Water 0800209 G009 1024

Figure 6. Comparison of observed (red curve) and simulated (black curve) for different duration Runoff calibration curve.

\subsection{Model Validation}

During calibration (previously selected does not consider the two different regions; model validation has been verified by six basin model. For each sample, the entire available historical monthly runoff series has been reproduced by the model and compared with the corresponding series of experiences, analyze the performance of the same index by model previously used.

Performance verification phase are similar between different catchments, very close to the basin in the calibration measurement, the NSE has a high value (average NSE $=0.74$ ) and low ME, ME / $\mathrm{Q}^{---}$ emp and RMSE for all six basins. Model Series regeneration larger basin (numbers 24,63 and 46) is slightly more accurate (average NSE $=0.79$ ) smaller than the (average NSE $=0.71$ ), but no significant differences in performance between the model validated I noticed the different sub-regions. The results show that: the ID 46 basin (sub-section C), the best performing 10-year sample size (ie the best NSE and RMSE), while the lowest performance in the wet basin (ID = 12 and 49), characterized in that the longest series (39-18 years of age, respectively).

Performance Model (NSE, ME, ME / $\mathrm{Q}^{---}$emp, RMSQ) in order to verify the size of the monthly basin. Identification number (ID), sub-regional, regional (A), for many years the simulation, observe family size (size), the observed average annual precipitation (MAP) also reported each pot. 


\section{C.Y.J. Chen}

Although verification basin characterized by rainfall runoff conversions that significant differences in the mean annual runoff coefficient from 0.14 (ID 43) to 0.34 (ID 49), the model has been shown in six pots, to capture a different watershed " hydrological response equal ability, high performance, can be listed in all of the basin, "good", there are two cases (for example, basin ID 24 and 46), or even "very good" (ie, NSE> 0.75).

Figure 6 shows a comparison of the observed and simulated precipitation sequence specific monthly runoff series (mm / month) for the six verified basin, report accordingly between. Simulation series is very close observation sequence, replication, and most of the peaks and nulls. Despite the significant differences in the two observed rainfall runoff, can be noticed between the basin side, model, and accurately grasp the monthly runoff variation is small (left) and larger (right panel) the three sub-basin -zones. For example, the ID 12 basin is characterized by a seasonal runoff system, about five months each year and almost dried frequent winter peak and about $100 \mathrm{~mm} /$ month water flow, and the ID 24 , characterized in that the behavior observed in the basin more regular runoff, and average rainfall less runoff, and having five months of $100 \mathrm{~mm} /$ month order runoff eight years; two basins models showed similar performance.

Water 08002091024 G010

Figure 6. Observation (trademark) and analog (dotted line) Monthly Runoff Series (mm / month) used to verify the basin, the histogram indicates the potential for precipitation series. Report only the first eight years. The figure refers to the sub-basin area A, B middle panel sub-regions of the basin, while the lower left panel of reference sub-region C. plates mean smaller basin (A <60 sq km), while the right panel is from the largest ( $\mathrm{A}>250^{\circ} \mathrm{C}$ square kilometers).

\subsection{Demonstration of different polymerization time scales}

Demonstrations in different times polymerization further evaluation, but also consider seasonal and annual time scales. This analysis has taken into account two basins 53 calibration verification and six pots deemed unique samples. More specifically, the monthly flow simulation has been gathered in the annual scale, also in the seasonal scale, taking into account the year is divided into two seasons: the dry season, from April to September and the wet season, the remaining six months of year.

11 from all areas of the model and the corresponding monthly water basin observation obtained, all estimated annual and seasonal runoff were compared. In the upper left panel of the figure, a total of 12,312 monthly runoff estimation theory plotted against the corresponding empirical value, and in another at the top of the scatter plot reference annual flow (middle panel value 1026) and the total average annual runoff of each basin (right, 59 value). The bottom panel of the empirical and theoretical dry season (left), during the rainy season, A similar comparison of total average season values and each basin runoff flow (right).

Water 0800209 G011 1024

Dry season months from April to September, while the wet season is the remainder of the year. The dotted line represents exactly the same observations and modeling values.

In the high predictive power of different polymeric scale model is the fact that, for all of the figures, most of the points is pretty near perfect agreement line (also reported in all of the figures), has a high value indicates that the coefficient of determination $\mathrm{R} 2$. These values are higher than the monthly level of 0.90 and greater annual level of 0.92 . Seasonal level, the model reproduces the dry season runoff during the rainy season and R2 values of 0.90 and $0.95 \mathrm{R} 2$. While the cloud point seemed to be more dispersed than in other circumstances, the size of each month get a high value of $\mathrm{R} 2$ can be 
explained by the presence of reproducing a considerable number of observations are the same model (ie, not null\% and 22 empty the water about $5 \%$ ).

Satisfied with the performance of the model has also been on a different river basin average annual, quarterly total to obtain a reproduction, as indicated by the resulting high value of R2 (ie, 0.95,0.89, and 0.92 for the dry season, the rainy season, the annual analysis, respectively) and lower average percentage error (from $2.2 \%$ for the year and the rainy season, to $12.5 \%$, for the dry season). In the ID 42 pots for the dry season $(\mathrm{AE}=0.21 \mathrm{in} \mathrm{mm} /$ season $)$, No. 37 during the rainy season $(\mathrm{AE}=0.02 \mathrm{in}$ $\mathrm{mm} /$ season), the best performance in terms of absolute error (AE) and ID 45 for the annual analysis $(\mathrm{AE}=0.34 \mathrm{~mm} /$ season), and the worst results in the No. 56 pots for the dry season ( $\mathrm{AE}=65 \mathrm{~mm} /$ season), and the ID 40 for the other two polymerization cycles (AE $121 \mathrm{Li} \mathrm{mm} /$ season and $135 \mathrm{~mm} /$ yr the rainy season and year, respectively). And result in the monthly scale, where ID 40 pots worst performance in two aspects I am a man previously obtained these values are consistent / $\mathrm{Q}^{---} \mathrm{emp}$

The results has, therefore, exhibit an increased capacity of the model to reproduce not only in runoff month scale and rough time resolution, exhibit a satisfactory ability to reproduce seasonal and inter Variety. A noteworthy aspect is that despite the use of three different types of sub-areas (ie, structures and different regression parameters of the same type for each) and 59 different boundary conditions of the application (ie, 59 different basins) under All estimates in all aggregate time scales analyzed, have shown comparable error, as can be seen from the left side and the intermediate plate 11 to.

In addition, in the rough time resolution, validate the model basin has performance results relative calibration basin, comparable with similar residuals. In the analysis used to verify the basin time scale, further deepening by comparing simulated and observed annual flow series, and calculate all the different performance of the previous month scale use. Comparative analysis of the results of this together, and for the main annual statistics (mean, standard deviation, minimum and maximum) of empirical and theoretical values, are synthesized.

Demonstration (NSE, ME, ME / $\mathrm{Q}^{---}$emp, RMSQ) in the year to verify the basin scale. Statistics (mean, standard deviation, minimum and maximum) observed (EMP) year also with the corresponding analog (Theo) value.

For most cases, all of the analog main annual statistics are very close to the observed value; moreover, it can be noted, has never been reproduced substantially higher than the variation observed. The annual performance index showed good agreement between simulated and observed annual flow series: highest NSE (0.96) of the ID 43 pots reach, while for the other basins NSE higher values were greater than 0.64 , the only exception is the number 46 pots, which are observed due to the relatively low efficiency of the series may have a negative impact on typical NSE low variance obtained (NSE = 0.26) (see the equation (3)). Other indices, in fact, the ID 46 represents the performance of a good model of the basin, the basin and the ID 12 has the lowest performance, and ME values other than ME / $\mathrm{Q}^{---}$emp slightly other basins, and also scope for obtaining RMSE value is relatively high.

\section{Conclusions}

This study applies to natural runoff series in a month or more coarse temporal resolution reconstruction region regression model, in-depth analysis of its performance. The importance of the development can be reproduced easily transferred from rainfall runoff model climate data reliability and long runoff series are appropriate and relevant facts are, in many practical situations, a runoff data set is non-existent or inadequate size, and long strings of data climate variables are used more often, and, then, may be utilized to fill the gap runoff records. Not available in parts of the stream or river is regulated estimate natural runoff dynamics practical approach is to involve some variety of sectors 
(for example, engineering, economic, environmental, etc.) on the basis of modern hydrological applications.

The idea in this paper is based on the realization of "soft" information basin, commonly available, such as rainfall, temperature, shape, or land-use knowledge rainfall runoff model calibration procedure. The model has been calibrated by a simple two-step procedure, the use of a considerable number of the Sicilian island basin, it has pots of different sizes and different climatic subregions be verified in the examination site on behalf of the six basins.

This application can be considered similar to a reference hydrological and climatic zones. By using the method described in detail, a number of practical issues, may be interested in the application of the model to other regions have been explored. For example, in this study, the performance of the model have been found if the area is considered to be divided into high three different sub-regions. In addition, six different pots property has proven to be defined function for rainfall runoff model parameter estimation of the timing of the regional equation. The same method applied to arid and semi-arid regions, different research areas of this work can be approached in different segments of interest and / or equations in different regions, which is characterized by different descriptions drainage area; however, rainfall runoff model, which before the regionalization steps, all of Sicily basin a particularly high precision by structure, is expected to be equally effective. On the contrary, when applied to wet areas should be included in the regression model is more appropriate to redefine the conceptual scheme, even if the presentation of the method can also be performed.

In this study we analyzed all the pots, regionalization model has been shown to meet the accuracy, by the different performance indicators to measure the reproducibility of different time scales observed aggregated quarterly and annual runoff from the monthly scale. Consider the monthly series reproduction Nash - Sutcliffe efficiency (NSE), which is quite weak, only two cases, but still positive (> 0.33), indicating a "behavioral" shape, and for the NSE index was higher than the other basins 0.50 , with a "satisfactory" $21 \%$ of cases, for the remaining $26 \%$ of the performance, "good" was $53 \%$, and "very good", according to the performance criteria given Moriasi et al. [60]. Rough time resolution, model performance did not show significant changes, errors in these two seasons, in any basin and ability to capture the seasonal and interannual changes in runoff, the average annual runoff of reproducing low percentage. Verify the robustness of the model's strong results, which, in the results of the model test of time scales all the history of the reproduction sequence runoff obtained confirm those obtained compared to calibration.

The results obtained show how the model discussed in this study can be considered in the estimation No information site for natural runoff time series of tips and the right choice. It is worth emphasizing that an important application of the model is currently being developed. In particular, a special plug-in is in the open source GIS software (ie, Quantum GIS 2.10) with the purpose automatizing data retrieval and processing program implementation. A suitable database management system (DBMS), plug-in support, the regional model, completely re-coded in the Python scripting language, after the initial preparation can quickly assess the natural runoff series (in months or more time scales) Sicilian any pots and any desired time window, both the Qiao realize a graphical user interface (GUI) to select. Plug-in will be based on a data processing module (DPM), which analyzes the use of space technology, with the first watershed classification (ie, sub-regional) and classification, the monthly time series of the average basis of the inference precipitation and temperatures, six basin model descriptor extraction, then at monthly runoff time series deduced. 

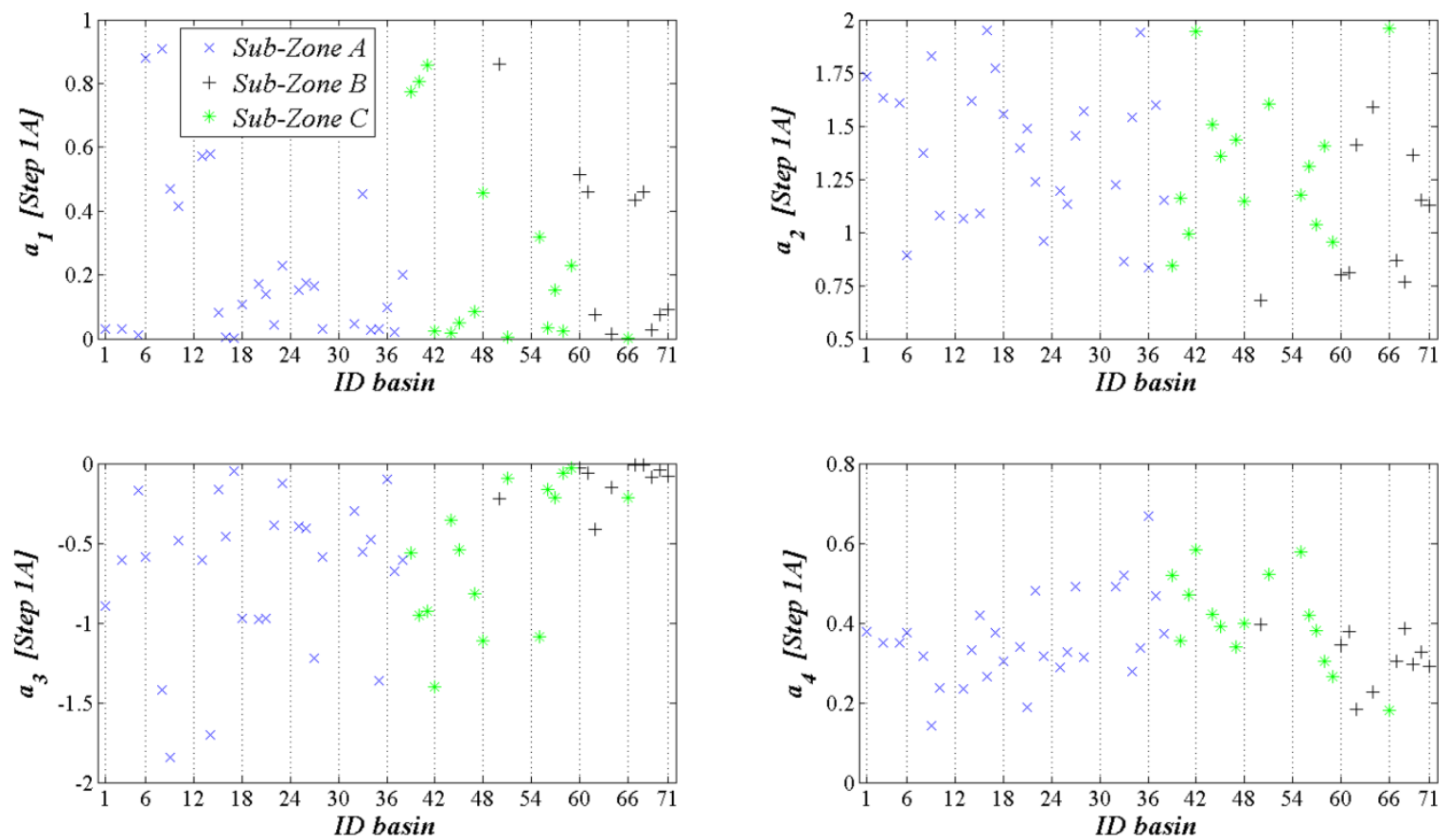

Figure 3. All calibration step basin $1 A$ optimum correction parameters (A1, A2, A3 and A4) after. Different markers for each sub-area.
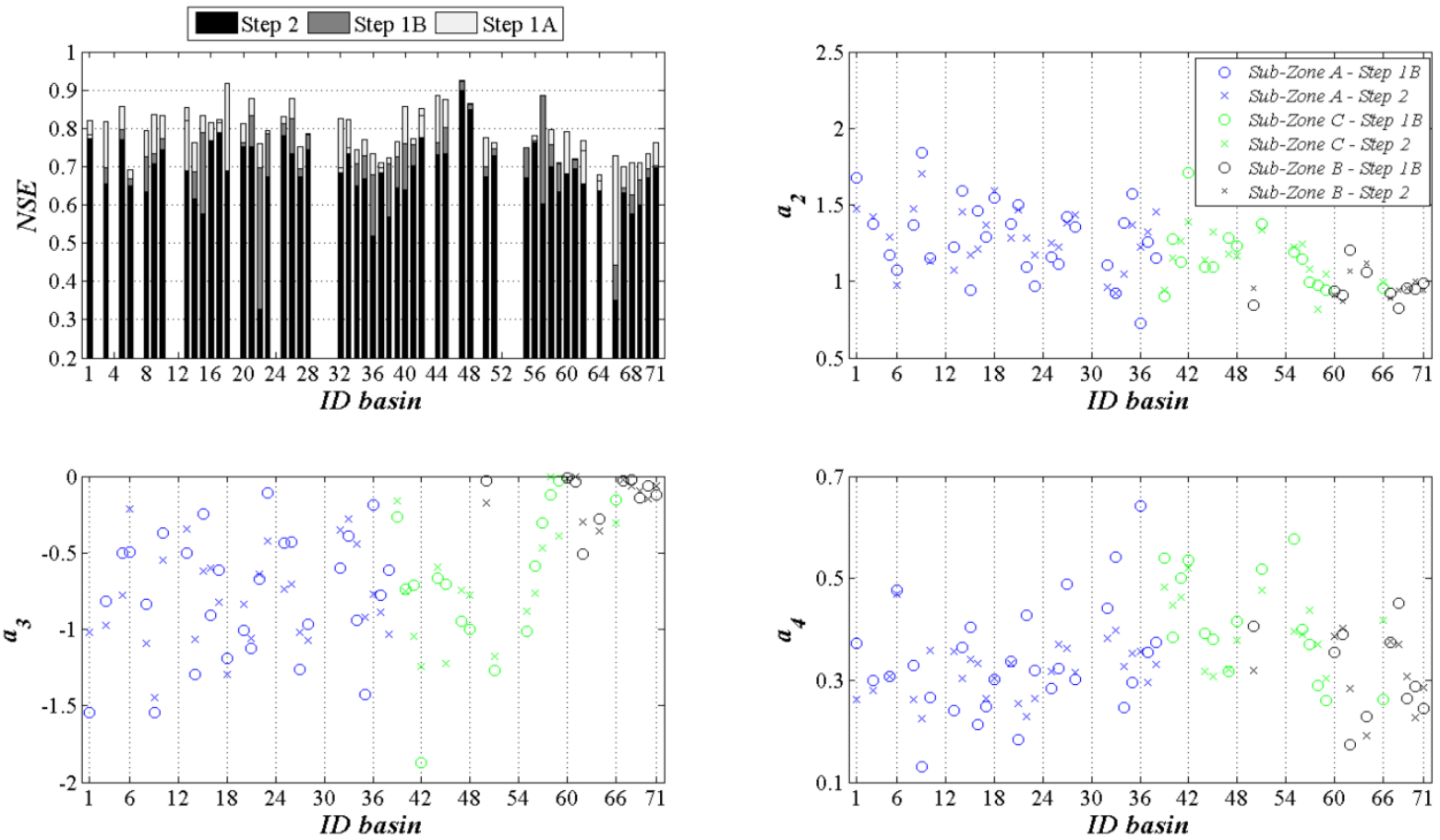

Figure 4. Performance parameters and models in different calibration stage: Best calibration parameters (A2, A3, and a4) Step $1 B$ and regionalization All calibration parameters Step 2 pots; histogram in the upper left corner, and the resulting value of NSE after each calibration phase 


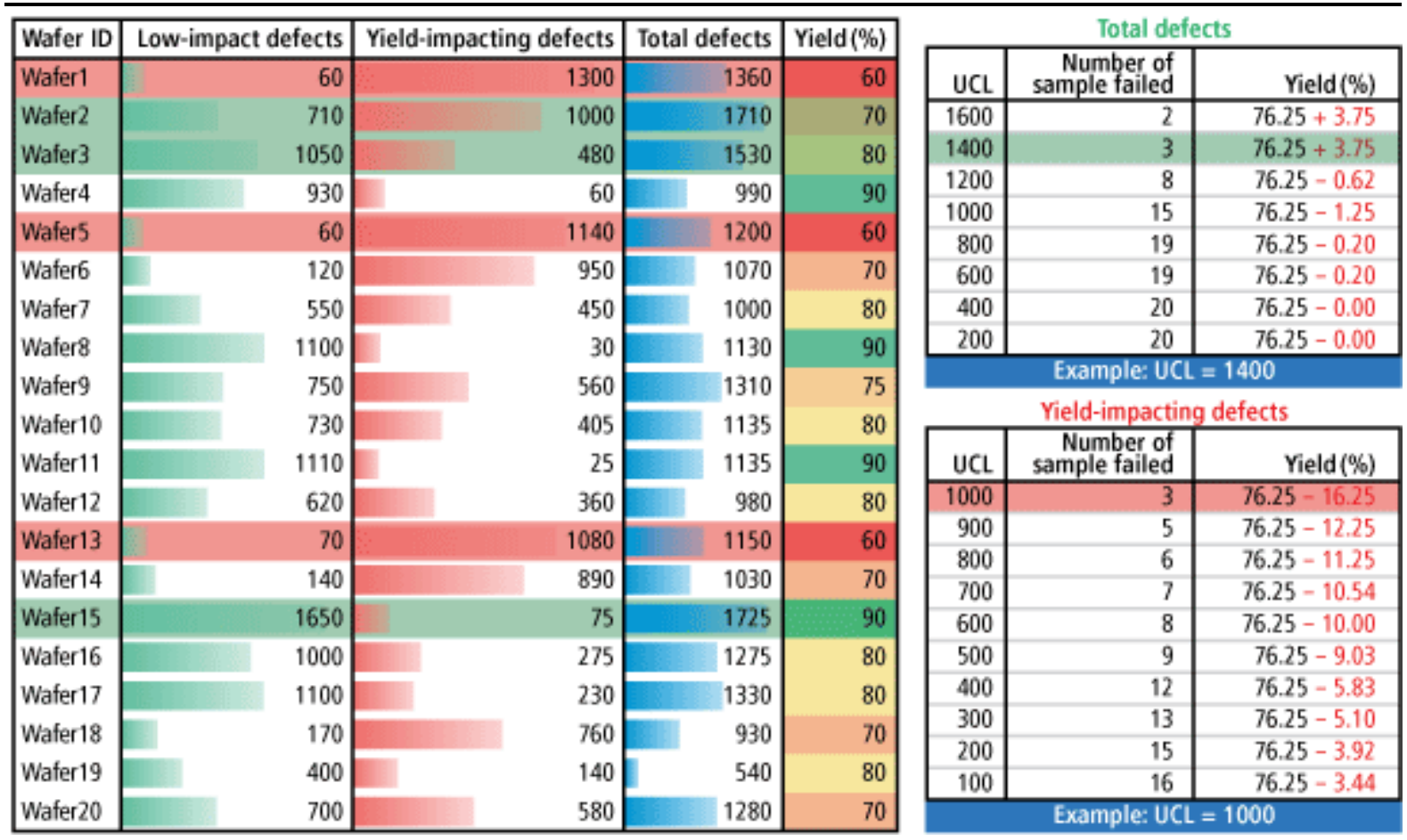

Figure 5. Comparison in Step 1 A (a), the model shows (NSE) comparing step 2 (b) below.
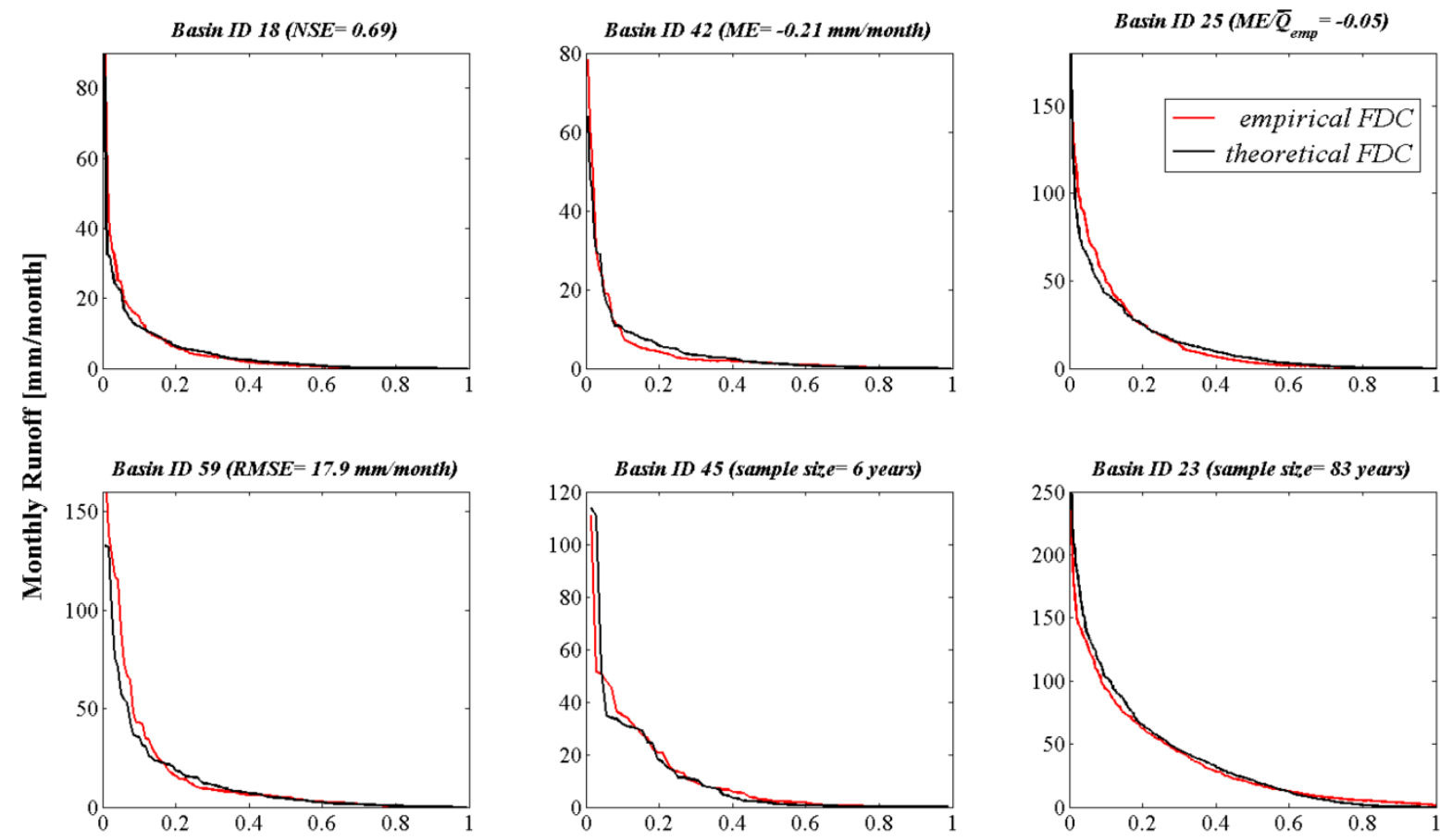

Exceedence Probability

Figure 6. Observation (red curve) and analog (black curve) for different durations of comparison between the calibration curve Runoff.

\section{ACKNOWLEDGEMENTS}

We gratefully acknowledge the financial support from King Abdulaziz University (KAU) Vice President for Educational Affairs and the KAU funding of Scientific Research, Jeddah, Saudi Arabia.

\section{Statement}

This paper is received on January 28, 2015 and accepted on March 5, 2016. The author would express the editor and reviewers' valuable comments for improvement to the manuscipt for publication in the Journal. 


\section{REFERENCES}

[1] Walker, B.; Holling, C. Resilience, adaptability and transformability in social-Ecological systems. Ecol. Soc. 2004, 9, 5.

[2] Holling, C.S. Adaptive Environmental Assessment and Management; John Wiley \& Sons: Chichester, UK, 1978.

[3] Cortner, H.; Moote, M. Trends and issues in land and water resources management: Setting the agenda for change. Environ. Manag. 1994, 18, 167-173.

[4] Pahl-Wostl, C.; Craps, M. Social learning and water resources management. Ecol. Soc. 2007, 12, 2007.

[5] Kallis, G.; Videira, N.; Antunes, P. Participatory methods for water resources planning. Environ. Plan. C Gov. Policy 2006, 24, 215-234.

[6] Crutzen, P. Geology of mankind. Nature 2002, 415, 23. [PubMed]

[7] National Environmental Policy Act (NEPA); 42 U.S. Code §4321; United States Federal Government: Washington, DC, USA, 1969.

[8] Clean Air Act (CAA); 42 U.S. Code \$\$7241-7671; United States Federal Government: Washington, DC, USA, 1970.

[9] Clean Water Act (CWA); 33 U.S. Code $\S 1251-1387$; United States Federal Government: Washington, DC, USA, 1972.

[10] Endangered Species Act (ESA); 16 U.S. Code $\$ \$ 1531-1544$; United States Federal Government: Washington, DC, USA, 1973.

[11] Hardin, G. The tragedy of the commons. Science 1968, 162, 1243-1248. [PubMed]

[12] Beall, A.M. Participatory Environmental Modeling and System Dynamics: Integrating Natural Resource Science and Social Concerns. Ph.D. Thesis, Washington State University, Pullman, WA, USA, 2007.

[13] Guttman, N. Bringing the mountain to the public: Dilemmas and contradictions in the procedures of public deliberation initiatives that aim to get "ordinary citizens" to deliberate policy issues. Commun. Theory 2007, 17, 411-438.

[14] Reed, M.S. Stakeholder participation for environmental management: A literature review. Biol. Conserv. 2008, 141, 2417-2431.

[15] O'Leary, R.; Bingham, L.B. The Promise and Performance of Environmental Conflict Resolution; RFF Press: New York, NY, USA, 2003.

[16] Dietz, T.; van den Belt, M. Forward. In Mediated Modeling; Island Press: Washington, DC, USA, 2004; p. xiii.

[17] Grumbine, R.E. What Is Ecosystem Management? Conserv. Biol. 1994, 8, $27-38$.

[18] Nagle, J.; Ruhl, J. The Law of Biodiversity and Ecosystem Management; Foundation Press: New York, NY, USA, 2002.

[19] Folke, C. Resilience: The emergence of a perspective for social-ecological systems analyses. Glob. Environ. Chang. 2006, 16, 253-257.

[20] Millennium Ecosystem Assessment. Available online: http://www.millenniumassessment.org/en/ index.html(accessed on 15 May 2016).

[21] Global Watership Partnership Technical Advisory Committee. Integrated Water Resources Management; TAC Background Paper; Global Water Partnership: Stockholm, Sweden, 2000. 
[22] Dörendahl, E.I. Boundary Work and Water Resources: Towards Improved Management and Research Practice? ZEF Working Paper Series, No. 122; Zentrum für Entwicklungsforschung: Bonn, Germany, 2013.

[23] Liu, Y.; Gupta, H.; Springer, E.; Wagener, T. Linking science with environmental decision making: Experiences from an integrated modeling approach to supporting sustainable water resources management. Environ. Model. 2008, 23, 846-858.

[24] Jacobs, K. Connecting Science, Policy, and Decision-Making: A Handbook for Researchers and Science Agencies; NOAA Office of Global Programs; NOAA Climate Diagnostics Center: Boulder, CO, USA, 2002.

[25] Beall, A.; Ford, A. Reports from the Field: Assessing the Art and Science of Participatory Environmental Modeling. Int. J. Inf. Syst. Soc. Chang. 2010, 1, 72-89.

[26] Bourget, E.C.; Langsdale, S.M.; van den Belt, M. Featured Collection Introduction: Collaborative Modeling for Decision Support as a Tool to Implement IWRM. J. Am. Water Resour. Assoc. 2013, 49, 605-608.

[27] Meadows, D.; Robinson, J. The Electronic Oracle; System Dynamics Society: Albany, NY, USA, 1985.

[28] Perez, E.M.; Viessman, W. The Role of Technology in Water Resources Planning and Management; Brown \& Caldwell: West Palm Beach, FL, USA, 2009.

[29] Voinov, A.; Bousquet, F. Modelling with stakeholders. Environ. Model. Softw. 2010, 25, 1268 1281.

[30] Winz, I.; Brierley, G.; Trowsdale, S. The use of system dynamics simulation in water resources management. Water Resour. Manag. 2009, 23, 1301-1323.

[31] Voinov, A.; Gaddis, E.J.B. Lessons for successful participatory watershed modeling: A perspective from modeling practitioners. Ecol. Model. 2008, 216, 197-207.

[32] Ford, A. Modeling the Environment: An Introduction to System Dynamics Modeling of Environmental Systems, 2nd ed.; Island Press: Washington, DC, USA, 2009.

[33] Johnson-Laird, P. Mental models in cognitive science. Cogn. Sci. 1980, 4, 71-115.

[34] Senge, P. The Fifth Discipline: The Art and Practice of the Learning Organization; Double Day: New York, NY, USA, 1990.

[35] Vennix, J.A.M. Group Model Building: Facilitating Team Learning Using System Dynamics; Wiley: Chichester, UK, 1996.

[36] Richmond, B.; Peterson, S. An Introduction to Systems Thinking; High Performance Systems: Hanover, NH, USA, 2001.

[37] Bourget, L. Converging Waters: Integrating Collaborative Modeling with Participatory Processes to Make Water Resources Decisions; Bourget, L., Ed.; Institute for Water Resources: Alexandria, VA, USA, 2011.

[38] Parson, E. Integrated assessment and environmental policy making: In pursuit of usefulness. Energy Policy 1995, 23, 463-475.

[39] Cardwell, H.; Langsdale, S.; Stephenson, K. The Shared Vision Planning Primer: How to Incorporate Computer Aided Dispute Resolution in Water Resources Planning; Institute for Water Resources: Alexandria, VA, USA, 2008.

[40] Costanza, R.; Ruth, M. Using dynamic modeling to scope environmental problems and build consensus. Environ. Manag. 1998, 22, 183-195.

[41] Cardwell, H.E.; Langsdale, S. Collaborative Modeling for Decision Support-Definitions and 
Next Steps. In Proceedings of the World Environmental and Water Resources Congress; Beighley, R., II, Kilgore, M., Eds.; ASCE: Reston, VA, USA, 2011; pp. 2805-2814.

[42] Van den Belt, M. Mediated Modeling: A System Dynamics Approach to Environmental Consensus Building; Island Press: Washington, DC, USA, 2004.

[43] Langsdale, S.; Beall, A.; Bourget, E.; Hagen, E.; Kudlas, S.; Palmer, R.; Tate, D.; Werick, W. Collaborative Modeling for Decision Support in Water Resources: Principles and Best Practices. J. Am. Water Resour. Assoc. 2013, 49, 629-638.

[44] Videira, N.; Antunes, P. Participatory modelling in environmental decision-making: The ria Formosa natural park case study. J. Environ. Assess. Policy Manag. 2003, 5, 421-447.

[45] Cockerill, K.; Passell, H.; Tidwell, V. Cooperative Modeling: Building bridges between science and the public. J. Am. Water Resour. Assoc. 2006, 42, 457-471.

[46] Creighton, J. How to Conduct a Shared Vision Planning Process; IWR Report 10-R-6; U.S. Army Institute for Water Resources: Alexandria, VA, USA, 2010.

[47] Lund, J.; Palmer, R. Water resource system modeling for conflict resolution. Water Resour. Update 1997, 3, 70-82.

[48] Langsdale, S.; Beall, A.; Carmichael, J.; Cohen, S.; Forster, C.; Neale, T. Exploring the implications of climate change on water resources through participatory modeling: Case study of the Okanagan Basin, British Columbia. J. Water Resour. Plan. Manag. 2009, 135, 373-381.

[49] Sheer, D.P.; Baeck, M.L.; Wright, J.R. Computer as negotiator. J. Am. Water Work. Assoc. 1989, $81,68-73$. 